Revista Iberoamericana, Vol. LXVII, Núm. 196, Julio-Setiembre 2001, 539-555

\title{
LA RETÓRICA DEL PERFORMANCE EN DIATRIBA DE AMOR CONTRA UN HOMBRE SENTADO DE GARCÍA MÁRQUEZ ${ }^{1}$
}

POR

\author{
Priscilla Meléndez \\ Penn State University
}

\begin{abstract}
[W]e are informed that performance, in only one of its many paradoxes, can deconstruct Presence utterly, and empower Absence or powerlessness. Since it is activated by non periodic, nonlinear activities-improvisation, play, transformation, parataxis, game structures-perfomance breaks down the illusion of rational control and power over meaning (and the structural metaphor of argument underlying the text), and substitutes a dispersal of order into disorganization.
\end{abstract}

—Michael Vanden Heuvel, Performing Drama/Dramatizing Performance

There is nothing more illusory in performance than the illusion of the unmediated.

$$
\text { - Herbert Blau, The Eye of Prey }
$$

Los estudiosos de la afamada y extensa obra narrativa y periodística del colombiano Gabriel García Márquez (1927) han puesto el énfasis crítico—con sobrada justificación— en conceptos narratológicos como "lenguaje”, “textualidad”, "narración”, “discurso” y "autoridad”, entre muchos otros que permean su obra. Sin embargo, la publicación y

\footnotetext{
${ }^{1}$ Utilizo el término en inglés “performance” y no "puesta en escena” siguiendo el análisis que ha hecho Diana Taylor sobre las múltiples acepciones de este vocablo tanto en inglés como en español: "En inglés 'performance' se ha utilizado generalmente para referirse a dos fenómenos que son esencialmente antitéticos. En su sentido más común, la palabra se podría traducir como puesta escénica o mise en scene. Si el teatro se considera un arte híbrido- texto y espectáculo-performance se definiría en oposición al texto dramático, un sub-género teatral. En su otro sentido, performance ha llegado a representar casi lo opuesto de teatro; se ha independizado para constituirse en diversas formas antiteatrales que resiten categorización: performance art, public art, instalaciones vivas, etcétera. En teoría, performance art rechaza la institucionalización del teatro e intenta subvertir un sistema de representaciones acusado de ser cómplice de un sistema social represivo" "Negotiating Performance", 49-50 traducción mía). Taylor concluye destacando que un tercer sentido del término que ha recibido menos atención es su concepción como "proceso mismo de teatralización social, el acto de asumir o re-presentar o atacar un rol proveniente de nuestros limitados repertorios sociales para fines que van más allá de lo estético" (50). Intentaremos demostrar en este ensayo que en el caso de Diatriba de amor estas tres concepciones del término "performance" entran en juego pero irónicamente terminan siendo cuestionadas e incluso parodiadas. A lo largo de mi trabajo colocaré siempre el vocablo performance en cursivas. A pesar de que utilizo a través de mi ensayo el término performer, cabe señalar el uso del vocablo "performero", el cual ya ha sido acuñado en distintos países y ambientes teatrales latinoamericanos. Por ejemplo, entre el 28 y el 31 de marzo de 1999 se celebró en la Universidad de
} 
representación en 1994 de la pieza dramática Diatriba de amor contra un hombre sentado del Nobel colombiano, ha obligado a los investigadores de su obra a cambiar momentáneamente de "discurso" para enfrentarse con las realidades físicas y visuales del teatro, y con las complejas estrategias comunicativas de éste. ${ }^{2}$ Entra así García Márquez en un medio artístico en donde su sagacidad lingüística e imaginativa tiene que conjugarse con realidades igualmente importantes como lo son las espaciales, dialógicas, cinésicas, histriónicas y de dinámica física.

No obstante, esta exploración del género teatral experimenta un nuevo giro de tuerca al darnos cuenta de que Diatriba de amor parece alejarse de ciertos aspectos del teatro tradicional para incursionar en el arte performativo que, como veremos, plantea una visión conflictiva tanto de la realidad textual de la obra como de lo que se ha considerado lo característicamente teatral: su nivel representativo y mimético; el énfasis en el sujeto; en el resultado más que en el proceso; la presunción de un significado; la presencia de un dramaturgo con poder y autoridad, de unos personajes representados por actores, y de espacios, tiempos y contextos lógicos y reconocibles. ${ }^{3}$

Puerto Rico, Recinto de Río Piedras, la cuarta edición del Simposio Caribe 2000 titulado “¿(con)Fusión cultural? Performance y performeros transcaribeños” (ver Grau). Mi agradecimiento al estudiante colombiano Luis Cano, quien a través de su trabajo final para el seminario graduado "Corrientes posmodernas del teatro hispanoamericano contemporáneo” en Penn State University, me dio la oportunidad de familiarizarme con esta pieza de García Márquez y reflexionar sobre ella. Igualmente agradezco a mi colega y amiga Amalia Galdhart su cuidadosa lectura de este ensayo y sus pertinentes recomendaciones.

${ }^{2}$ Diatriba de amor contra un hombre sentado fue escrita en 1987 y publicada en 1994. Esta edición nos indica que la obra fue estrenada en Colombia en el Teatro Nacional el 23 de marzo de 1994 como parte del IV Festival Iberoamericano de Teatro (8). Fue cooproducida por el Teatro Libre de Bogotá, el Teatro Nacional y el Instituto Colombiano de Cultura (8). Cabe señalar que el rápido acceso que algunos afamados narradores hispanoamericanos contemporáneos_-Vargas Llosa, Carlos Fuentes, Manuel Puig — han tenido para publicar sus escasas piezas de teatro, ha causado cierta desazón entre los estudiosos de este género, por considerar que importantes dramaturgos de esta región no han tenido igual acceso a las casas editoriales y que sus textos dramáticos circulan con bastante dificultad. No se trata de desacreditar aquí a los novelistas que con todo derecho incursionan en el género teatral, sino de subrayar la necesidad de abrirle aún más las puertas de la publicación a los dramaturgos hispanoamericanos "bona fide".

${ }^{3}$ En contraste con esta visión tradicional del teatro, Michael Vanden Heuvel subraya el rechazo del texto y la consecuente valoración del performance como el cambio más radical y potencialmente subversivo dentro del teatro experimental de la década de los sesenta: "Performance, it was theorized, promised the perfect antiauthoritarian response to the repressive authority of the text and to the power structure that controlled the rationalist language within it. It was also the quickest path to subverting the intellectual bases of drama, with their mind/object distinction, quantified sense of time, and psychological development of character. And aside from its potential for disrupting the essential structures, political bases, and production processes of bourgeois drama, performance also promised an alternative to traditional aesthetics built on conventional notions of semiosis” (34). Por su parte, Marvin Carlson refuta la idea de que el arte performativo de la década de los setenta en los Estados Unidos estuviera desvinculado de planteamientos en torno al ser, la historia, la política y la estética (151). Igualmente, Taylor, al destacar que el foco del arte performativo se encuentra en lo hermético y lo privado, más que en lo público, aclara de inmediato: "None of this is to suggest that performance art is less political than public art or public performance. But it is often political in a different, more private way” (“Opening Remarks” 11-12). 
En un primer nivel, el receptor de Diatriba de amor se enfrenta con un monólogo dramático en donde García Márquez coloca a una mujer de clase alta en escena y ésta, a su vez, va a narrar teatralmente su larga y frustrada relación matrimonial. Sin mayores dificultades reconocemos aquí la presencia de un texto, de un sigular autor y de la dramatización de una historia personal que nos permite conceptualizar la obra dentro de ciertos parámetros tradicionales del teatro. Bajo esta concepción, es posible interpretar el monólogo de Graciela como una mera diatriba contra un marido apático y silente, es decir, como un monólogo que sigue los esquemas tradicionales de una obra dramática con acotaciones, juegos escénicos, un espacio teatral reconocible y un autor quien juega con la idea de esconder y a la vez revelar su identidad y poder autorial tras la máscara de sus personajes. $^{4}$

Sin embargo, lo que resulta particularmente original en Diatriba de amor es ver cómo la construcción de Graciela_-protagonista única_-parece representar una ruptura con el propio espacio en donde ésta es creada y desarrollada. Es decir, se trata de un personaje dramático que irónicamente rompe con el tradicional espacio teatral que ocupa, siendo esta ruptura lo que nos llevaría a interpretar el monólogo, no como mera diatriba contra un marido indiferente, sino como un consciente acto de performance. Podríamos decir entonces que el significado de esta ruptura radica en sustituir la ausencia de comunicación física, espiritual y escénica del personaje de Graciela, por el parloteo y la aparente retórica antiteatral y antisocial de la performer. Bajo esta luz, Graciela es construida como personaje de un drama, pero su construcción dramática pretende subvertir su realidad como personaje para destacar más bien su complejo perfil de mujer performer. ${ }^{5}$ Sin embargo, Diatriba de amor no parece conformarse con transformar a Graciela de personaje a performertransfromación que destaca su adquirida autoridad—sino que es a través de la propia Graciela que irónicamente se cuestiona y desmantela dicho perfil, revelándose así la compleja y a veces contradictoria naturaleza del género del performance. Resulta evidente entonces, que el espectador de Diatriba va a enfrentarse con una pluralidad de textos-entre ellos, el texto dramático de García Márquez, la diatriba de Graciela-personaje, y la (re)presentación de Graciela como performer-, "textos” cuyas identidades parecen

\footnotetext{
${ }^{4}$ En su libro Postmodern Theatric[k]s: Monologue in Contemporary American Drama, Deborah R. Geis subraya la poca atención crítica que ha recibido la tradición del monólogo en términos de su efecto en la narración dramática o el lugar que ocupa dentro de la estructura dramática. Pero sobre todo, Geis cuestiona cómo en distintos estudios sobre el diálogo en la tradición teatral, el monólogo ha sido caracterizado, no en sus propios términos, sino más bien como ausencia de diálogo: "yet, in these two studies [by Ruby Cohn and Andrew Kennedy] monologue inevitably becomes the absent opposition, the implicit other to which dialogue is compared" (2). Más adelante, examinaremos la relación que se establece en Diatriba de amor entre el uso del monólogo y el supuesto carácter (anti)verbal del performance.

${ }^{5}$ Según Jeanie Forte es posible caracterizar este perfil y ver a la mujer performer, entre otras cosas, como desconstructora del papel de la mujer como objeto (252); como figura que reta el discurso de la representación - discurso que sostiene las jererquías tradicionales basadas en la relación entre el poder y el conocimiento (253-54); como sujeto hablante (254-55); y como voz autobiográfica que cuestiona la construcción y representación de la categoría “mujer” y el vínculo de esta categoría con la sexualidad (259). Sería igualmente necesario examinar el grado de performance que existe en la identidad o constitución del género sexual.
} 
contradecirse entre sí y cuyas posturas autoritarias y visiones autoriales terminarán siendo cuestionadas.

No nos sorprende entonces que la tensión entre la textualidad y teatralidad de la pieza frente al nivel performativo de ésta sea uno de los ángulos importantes que se problematizan en Diatriba de amor y que estaremos examinando a lo largo de este trabajo. ${ }^{6}$ Según intentaremos demostrar, la pieza de García Márquez caracteriza en escena el conflicto entre estos discursos en apariencia opuestos: por un lado, la concepción tradicional del texto dramático como una actividad cognoscitiva que le impone estructura o significado a la realidad (Vanden Heuvel 3), y por otro, el discurso performativo que, como señala el propio Vanden Heuvel, intenta rebelarse contra la visión cerrada del texto, procura quebrar las distinciones tradicionales entre arte y vida, defiende la primacía del actor/performer frente al autor, y desea privilegiar la voz humana por sobre la palabra escrita (ver 23, 31, 45, 46).

No obstante, la particularidad de Diatriba de amor es que al contraponer la presencia de un texto dramático con la aparente antitextualidad y antiteatralidad del discurso performativo, García Márquez termina estableciendo una relación a la vez antagónica y complementaria entre estas formas de comunicación, recreando y desmantelando así tanto la autoridad como la ausencia de ella, el poder como la falta de éste, el lenguaje verbal como el físico, la escritura como la oralidad, el parloteo como el silencio. En última instancia, lo que procuraremos demostrar es que las dos perspectivas de Diatriba de amor que destacamos aquí-Diatriba como texto dramático o bien como acto performativo-se entremezclan como mecanismo para cuestionar los parámetros y las expectativas de cada uno de estos discursos y del arte en general. Es decir, la pieza de García Márquez puede ser vista entonces como un texto dramático que asume la identidad de un performance, no siéndolo, con el propósito de explorar los propios instrumentos textuales y antitextuales, teatrales y antiteatrales que permean el arte y la vida, y que en el caso de la amplia producción narrativa del escritor colombiano también subrayan conflictos de poder y autoridadconflictos que van a ocupar un lugar céntrico en nuestro análisis a través del choque entre la dinámica escénica y (seudo)feminista de Graciela como personaje y como performer, y el implícito vínculo de ésta con la figura autorial, masculina, afamada y supuestamente pasiva de Diatriba de amor contra un hombre sentado. ${ }^{7}$

\footnotetext{
${ }^{6}$ Vanden Heuvel destaca la importancia de ver el performance como un mecanismo que constantemente procura dislocar el poder del texto dramático (71), sin lograr, no obstante, una dislocación definitiva. ${ }^{7}$ Es sabido que a lo largo de su producción narrativa, García Márquez se ha enfrentado directamente con el tema de la autoridad del propio escritor y del control que éste ejerce sobre la realidad artística y social que lo rodea. El reconocimiento implítico y explícito de elementos autobiográficos en muchas de sus obras-Cien años de soledad (1967), Crónica de una muerte anunciada (1981), El amor en los tiempos del cólera (1985) y Doce cuentos peregrinos (1992), entre otras-revela una persistente reflexión en torno a su presencia y poder textual y extratexual. Nos parece significativo que García Márquez incursione en el teatro contraponiendo precisamente dos discursos que parecen representar fuerzas opuestas en torno a la problemática del poder y la autoridad creativa: por un lado, el poder textual y autorial (incuestionable en el género narrativo), y por otro el escénico, que en el caso del teatro es compartido por múltiples figuras, voces y estructuras que forman parte del proceso teatral como lo son el director, el productor, el director escénico, el luminotécnico, o incluso la posibilidad de creadores colectivos.
} 
Al regresar con su esposo de una cena informal en la madrugada de sus bodas de plata el 3 de agosto de 1978, Graciela le increpa largamente a éste en el dormitorio de ambos sobre su historia e infelicidad matrimonial, reconstruyendo-para el marido sentado que finge leer el periódico y para el público que escucha—el origen y desarrollo de esta relación. A través de frecuentes cambios de vestuario, que evocarán cambios de lugar, de tiempo y de ambiente, Graciela le increpa ferozmente a su marido la vaciedad de sus vidas y la profunda ironía de celebrar esa noche, con una gran fiesta, lo que será para ella su último aniversario. La propia Graciela lee en el periódico vespertino las noticias sobre esta celebración: "Más de mil invitados nacionales y extranjeros, cuatro quintales de caviar, sesenta bueyes artificiales importados del Japón, toda la producción nacional de pavos, y alcoholes suficientes para resolver la penuria de la vivienda popular” (14).

A través de un intenso monólogo, Graciela nos va remontando paulatinamente a su origen humilde y lo contrasta con el ambiente de abundancia en donde se ha criado el marido. Con aplomo, Graciela va quitándose el maquillaje frente al público y va cambiando de lugar el mobiliario, hasta transformar el dormitorio de ricos "en una habitación pobre de una barriada del Caribe, con muy escasos muebles rústicos y maltrechos”(21). Nos describe con amargura y humor irónico cómo van entrelazándose sus contradictorias vidas durante los primeros años de matrimonio—que se caracterizan por la pobreza—, hasta seguir rumbos diferentes cuando viven en la abundancia económica.

Sus acusaciones contra el marido y contra su deteriorada relación no van a cesar en ningún momento y, sobre todo, Graciela se va a empeñar en que sepamos los extremos a los que ha llegado para hacerse digna de él. Por ejemplo, en su intento de elevar su estatus (resolviendo particularmente su defecto de dicción), Graciela se inserta en el mundo de la intelectualidady, además de doctorarse cuatro veces, saca dos maestrías, siendo irónicamente una de ellas en retórica y elocuencia. Lo hiperbólico y humorístico de este intento de adquirir méritos ante su marido y ante la sociedad a la cual no pertenece, parece desinflar la pesada historia de su vida y además parece inyectarle a la obra un cierto grado de intranscendencia que, a su vez, contrasta con la supuesta rebelión feminista de la protagonista y con el ambiguo y abierto final de la pieza. ${ }^{8}$ Luego de perorar sobre su embarazo previo al matrimonio, sobre la tensión con la familia del esposo, la persistente infidelidad de éste, y sobre el distanciamiento y la indiferencia del hijo, al final de su diatriba ocurre algo sorpresivo: Graciela enciende con un fósforo el periódico que lee el “esposo inmóvil”, quien comienza a ser “consumido por las llamas” (68).

¿Ha asesinado Graciela a su marido, “autor” de su desgracia? ¿Interpretamos esta acción final como un gesto heroico contra su supérfluo pasado? ¿Se trata de un rechazo rotundo de lo verbal, que ha dominado hasta ahora la vida de Graciela y que también ha dominado la representación que hace de sí misma? ¿Se ha decidido finalmente Graciela a

\footnotetext{
${ }^{8}$ Resulta de interés destacar los comentarios de Vanden Heuvel sobre el carácter anti-intelectual de ciertos performances de las décadas de los sesenta, y especialmente de los setentas (48). Vemos entonces cómo esta burla a la intelectualidad de Graciela—sus problemas de dicción, sus abundantes grados académicos y su relación con sus admiradores (seudo)intelectuales—se vincula indirectamente con las antagónicas expectativas entre drama y performance: el primero, en su intento por desplegar su carácter trascendente, racional e intelectual, y el segundo, en su búsqueda de un discurso antiautoritario, antijerárquico y, en ocasiones, intrascendente.
} 
sustituir la diatriba por el énfasis en la acción? Sin embargo, estas preguntas parecen un tanto supérfluas cuando consideramos que, según indica la primera acotación del texto, el marido que escucha la perorata a la vez que lee el periódico sentado en un sillón, será representado por un maniquí quien, por supuesto, va a permanecer quieto y en silencio a través de toda la obra: "En el extremo derecho, sentado en un sillón inglés, en traje oscuro y con la cara oculta detrás del periódico que finge leer, está el marido inmóvil. Es un maniquí” (10). ${ }^{9}$

Es precisamente esta compleja representación del marido lo que nos induce a preguntarnos qué consecuencias tiene para esta obra el hecho de que el receptor primario de la perorata sea un maniquí. ¿ ¿Hasta que punto esta problemática realidad escénica nos obliga a replantear el acto destructivo al final de la obra, es decir, el "asesinato” del marido, sobre todo cuando la propia Graciela no se da cuenta de que el fuego se ha propagado del periódico al esposo inmóvil? ¿Podemos suponer que este replanteamiento del desenlace nos hace reconsiderar tanto el comienzo de la obra como la propia identidad de ésta? ¿Se transforma este "asesinato” de un acto de rebelión vital a uno de carácter puramente teatral, o tal vez viceversa? ¿Ejecuta Graciela un acto de valentía y liberación al matar al marido, incluso sin darse cuenta, o lo interpretamos como un acto de cobardía al saber que es un mero maniquí? ¿Qué implicaciones tendría una interpretación simbólica del asesinato?

No cesan aquí las interrogantes y la obra nos induce a formular aun más preguntas. ¿Intenta Diatriba decir algo sobre la dinámica entre representación y receptor, al enfrentarse este último a la disyuntiva de que el hombre consumido por las llamas sea el marido de Graciela, o una representación ficticia de éste? ¿Podríamos ver el periódico como la máscara o cortina tras la cual se esconden el marido, o el autor, o el receptor en un intento de reformular sus respectivas identidades? ¿ $\mathrm{O}$ se trata tal vez de caricaturizar la quema del periódico y del marido como emblema de la desaparición del texto y del autor? ${ }^{10}$ ¿Podemos interpretar esta posible desaparición como una acción de carácter antiteatral y antiinstitucional, es decir, como un acto de rebeldía contra los esquemas rígidos del arte y contra sus tradicionales expectativas: contra una clausura lógica, un receptor vivo, un contexto histórico, un creador que controla desde fuera la acción? ¿Concebimos entonces esta rebeldía como el intento de transformar un tradicional discurso dramático en uno antidramático, coqueteando así con la idea de que se trata de un performance? ¿Cuál es, en última intancia, la identidad de Diatriba de amor contra un hombre sentado?

A lo largo de su estudio Performing Drama/Dramatizing Perfomance, Vanden Heuvel nos recuerda precisamente la cambiante relación entre texto dramático y performance desde perspectivas artísticas e históricas. A partir de la década de los sesenta el término performance deja de ser definido como la representación del artefacto literario y cesa de

${ }^{9}$ Cabe recordar aquí que algunos podrían argüir que la acotación no necesariamente tiene que ser obvia de inmediato para el espectador, pero también debemos suponer que tarde o temprano éste se dará cuenta de que se trata de un muñeco.

${ }^{10}$ El prestigio de García Márquez como periodista es harto conocido, y no nos parece casual que en una obra donde la problemática textual y anti-textual ocupa un papel céntrico, se ejecute la muerte de un hombre, o bien la destrucción de un maniquí, a través de la quema del periódico. También aludo aquí al conocido ensayo de Roland Barthes, “The Death of the Author”, el cual propone que el acto de escribir implica la desaparición del sujeto que escribe: "[W]riting is the destruction of every voice, of every point of origin. Writing is the neutral, composite, oblique space where our subject slips away, the negative where all identity is lost, starting with the very identity of the body writing” (142). 
estar implicado en la reconstitución de un determinado significado y de un poder autorial (Vanden Heuvel 4). Más bien pasa a ser concebido como un medio teatral autónomo e inorgánico, una alternativa al drama literario, y un mecanismo para desconstruir la visión del autor como presencia y poder: "Performance deconstructs authorial power and its illusion of Presence, and disperses its quanta of energies among the performers and the spectator as a potential source of deferred, hypothetical, and immanent power. Performance is therefore initially the displacement of Presence, or power, and the affirmation of Absence and powerlessness" (5). Sin embargo, luego de caracterizar el frecuente choque durante las últimas décadas entre drama y performance, Vanden Heuvel destaca el espacio interactivo que ha ido desarrollándose a partir de un renovado diálogo entre ambos discursos (19, 110, 113).

Igualmente cabe destacar que en el marco de los estudios sobre performance, la compleja figura del performer es concebida, entre otras cosas, como un ser autónomo e independiente que con frecuencia le presenta a un público material autobiográfico sin aparentes mediaciones de índole teatral. Dentro de este marco teórico, se subraya también que la relación del artista con su propio performance no es la misma relación del actor con su papel: "When he refuses to be a protagonist, the performer no more plays himself than he represents himself. Instead, he is a source of production and displacement” (Vanden Heuvel 173). Por otro lado, el énfasis en el aspecto corporal y físico del performer se constituye en elemento básico del performance, destacando a su vez el aparente rechazo del elemento verbal y textual de la pieza. Es por ello por lo que, en un primer nivel y bajo esta caracterización de la figura del performer, podríamos decir que Graciela lucha contra la posibilidad de ser caracterizada como la protagonista de una obra dramática cerrada y coherente, e intenta proyectarse como un ser que instituye un espacio indeterminado y abierto que en aparencia es creado por ella, y que a la vez es reflejo de su realidad vital y artística. Sin embargo, veremos adelante que la rebeldía de esta postura también termina siendo teatralizada y cuestionada por la propia obra, problematizándose así tanto el perfil de Graciela-performer como el del propio performance.

Es posible anticipar entonces que el juego irónico de la pieza de García Márquez es crear dos voces simultáneas—la teatral y la performativa—que a la vez se contradicen y se complementan. Por un lado, y desde una perspectiva textual y teatral, vemos cómo Diatriba tematiza aspectos de la comunicación tanto oral como escrita al colocar en escena a una mujer que no cesa de hablar y de increparle al marido que lee el periódico las infidelidades e indiferencia de éste. Destacamos incluso que es a través del periódico que lee el marido silente que Diatriba emblematiza su textualidad, es decir, su vínculo con la palabra escrita y con el tradicional acto de lectura (al cual nos tiene tan acostumbrados el afamado escritor colombiano). Sin embargo, esta textualidad queda problematizada cuando reconocemos que el control verbal de Graciela y el predominio de lo oral representan tanto el cuestionamiento que hace este texto dramático de su propia y anticuada textualidad-la cual no podemos pasar por alto una vez sabemos que el marido está leyendo un periódico del día anteriorcomo el cuestionamiento del carácter ritualista y vacuo del acto de lectura representado por el marido/maniquí.

Por otro lado, y desde la perspectiva del arte performativo, nos enfrentamos a través de Diatriba de amor a un acto que pretende despojarse de su tradicional vestuario de obra 
representada (en donde la protagonista es tradicionalmente una mera marioneta), con el propósito de asumir otras identidades que fluctúan entre el desmantelamiento del poder autorial, el escénico y el socio-moral. Más que crear una imagen de una puesta en escena donde un autor conocido construye una imagen femenina y feminista del personaje principal, la obra pretende enmascarar juguetonamente su identidad de texto dramático tras el acto performativo, el cual ha sido visto como antagónico a la actividad teatral por considerarla parte de un discurso institucional, parte de una estructura limitante y autoritaria. Sin embargo, más que establecer un vínuclo antagónico entre texto dramático y performance, Diatriba de amor paradójicamente despliega y a la vez desmitifica en escena tanto el carácter textual y teatral de la pieza como los parámetros del arte performativo.

Es justamente al reflexionar en torno a los aspectos que podrían considerarse como antiteatrales y anti-institucionales en Diatriba de amor que acudimos necesariamente al medio comunicativo principal de la pieza de García Márquez—el monólogo. ${ }^{11}$ En primera instancia es evidente que el énfasis en la construcción verbal de este "Monólogo en un acto", subrayado en la cantaleta que Graciela lanza contra su marido, establece una tensa relación con el carácter dramático, histriónico y corporal de esta diatriba. Suponer que sólo un personaje va a narrar la historia de su vida en escena y que el interlocutor es un hombre sentado y silente, sugiere de antemano que la pieza va a problematizar ciertas expectativas teatrales de carácter tradicional como lo es el diálogo y el movimiento escénico. Es decir, ha sido una práctica común asociar el exceso verbal, sobre todo de carácter denunciativo como lo es una diatriba o cantaleta, con lo antiteatral, y a su vez contraponerlo con el énfasis en lo cinésico y proxémico. ${ }^{12}$ Precisamente al examinar la presencia de la narración en el arte dramático hispanoamericano, John Kronik señala: “The split [between drama and

${ }^{11}$ Geis examina los ángulos históricos y teóricos del uso del monólogo en el teatro contemporáneo destacando, sobre todo, cómo su estatus de discurso performativo se convierte en una vía efectiva para que el dramaturgo le imprima al texto dramático una voz narrativa. El conflicto en torno al uso del monólogo surge momentáneamente cuando establecemos un vínculo entre éste y el performance. Por un lado, Geis señala que el monólogo exige que coloquemos nuestra atención en el sujeto (10)—lo que implicaría cierto antagonismo con los paradigmas de la actividad performativa, pues según señala Josette Féral: "Performance is the death of the subject” (173). Sin embargo, algunas de las facetas más recientes del performance han abandonado las piezas de múltiples personajes que en cierto sentido preservan un marco ficcional, en favor de unos performers que hablan exclusivamente a través de la voz monologal en un modo semiautobiográfico que ha sido denominado como autoperformance (Geis 4). Forte nos recuerda que desde la perspectiva del arte performativo de mujeres, se exalta a la mujer como sujeto hablante-como voz alternativa y heterogénea-, en contraposición a la concepción tradicional de un sujeto (masculino) singular y unificado (254).

${ }^{12}$ Sin embargo, vemos dentro del más experimental discurso performativo instancias en que esta tensión entre lo verbal y lo físico ha sido llevada a los extremos como parte de unas estrategias radicalmente antiteatrales. Por ejemplo, al describir ciertas facetas del arte performativo de la década de los setenta, Carlson comenta sobre un grupo de teóricos quienes, en contraposición al concepto de postmodernidad, continuaron separando las artes con el propósito de encontrar y desarrollar la "esencia" de cada una de ellas: "Such performance sought what might be characterized as a physical rather than a psychic essentialism. Like Artaud, this performance rejected the 'theatrical' trappings of discursive language, narration, and character, but in the name of minimalism and anti-theatre it also rejected Artaud's interest in non-verbal spectable, seeking the 'essence' of preformance in the operations of the body in space" (126). 
narrative] has given rise... to a strong public bias against a theatre regarded as 'wordy' and discursive...” (25-26).

Sin embargo, la dimensión histriónica y física de Diatriba de amor se caracteriza precisamente al contraponer y a la vez entrelazar la paródica verbosidad de Graciela con la fogosa actividad escénica que ella genera y que cobra vida, como hemos sugerido, a través de los cambios de vestuario, el juego de luces y sonidos, el énfasis tanto en el aspecto musical como en el mobiliario, y en el aparente diálogo con otros personajes. Es pues esta falsa dicotomía entre lo verbal y lo corporal lo que nos conduce a explorar el concepto de performance en su compleja relación con la textualidad, a examinar las frecuentes reformulaciones de ambos discursos, pero sobre todo, a indagar en las falsas expectativas de estos dos medios comunicativos:

Despite the enormous variety of performance activities during the 1970s and 1980s, it is possible to trace two over-all and related trends. First, the initial wide-spread opposition of performance to theatre has steadily eroded; and second, the initial emphasis on body and movement, with a general rejection of discursive language, has given way gradually to image-centered performance and a return of language. (Carlson 116)

Es por ello por lo que, como parte de esta tensa y complementaria relación entre textualidad y performance, entre lenguaje y actividad corporal, tampoco nos sorprende que, a pesar de la intensidad dramática y emocional que alcanza la pieza de García Márquez a través de una mujer que nos presenta su versión de 25 horribles años de matrimonio, el propio título de esta pieza coloque el énfasis en dos aspectos en apariencia antiteatrales. Por un lado, Diatriba de amor contra un hombre sentado se regodea en exaltar la retórica y el exceso verbal, y por otro, subraya la inacción física y emocional a través de la presencia de un hombre sentado quien parece más bien formar parte del mobiliario. Como hemos sugerido, es precisamente la aparente antiteatralidad de una diatriba en escena uno de los aspectos que vincula la obra con el arte performativo, pues presupone un rechazo de las mencionadas estructuras tradicionales que caracterizan la producción dramática: diálogo, textualidad, autoridad y poder. Desde una perspectiva igualmente paradójica, el concepto de diatriba-“'AAtaque. Invectiva'. 'Discurso o escrito que contiene injurias o una censura violenta contra alguien o algo”” (Moliner 990)—establece un contraste con el término que lo modifica—amor—como forma de problematizar el carácter antitético del juego entre lo verbal y pasivo y lo corporal y activo, juego que se extiende para incluir lo presente y lo ausente, el orden temporal y espacial frente al caos, la autoridad de un individuo sobre otro frente a la autonomía de cada uno de ellos. ${ }^{13}$

Como es de suponer, el predominio de lo ausente en Diatriba-ausencia de amor, de diálogo, de respeto-metaforiza la propia ausencia de un interlocutor. El hecho de que el marido/maniquí de Graciela (ricacho, mujeriego y mentiroso) no interactúe ni verbal ni físicamente con su esposa subraya esta dinámica entre lo presente y lo ausente, y entre los que poseen y los que no poseen el poder escénico, económico y social. Se subraya así la

${ }^{13}$ En ocasiones he sustituido la palabra "diatriba” por el término cantaleta en su acepción hispanoamericana — Cantaleta: "Repetir insistentemente las cosas" (Moliner 496)—, y por el vocablo perorata: “Despectivo de peroración; exposición de ideas u opiniones, larga y pesada” (Moliner 712). 
posibilidad de ver Diatriba de amor como un intento de desplazar todo aquello que represente cierto control sobre alguien o algo, tanto en un plano familiar como social, escénico como psicológico, textual como extratextual. En un primer nivel, presumiríamos entonces que el silencio y la inmovilidad del marido son una forma de despojarlo de autoridad, que en manos de la performer será compartida con aquellos que la escuchan: "Ya fuera del personaje, pregunta al público: ¿Alguien recuerda qué estaba diciendo? Las respuestas del público le permiten recuperar el hilo del monólogo...” (29).

No obstante, son precisamente las evidentes contradicciones de Graciela como performer, es decir, como un ser que debía ser consciente de su postura antiteatral y antiautoritaria, las que se manifiestan en la próxima frase al reclamar ésta su poder y autoridad: "pero antes les dice a quienes la ayudaron a recordar: Mil gracias, pero al fin y al cabo es mi marido, y este pleito es sólo de él y mío, y nadie tiene que meterse. ¿Perdone, eh?” (29). Graciela, como autora y performer de esta diatriba, pretende crear un sentido de inmediatez y realidad, y de otorgarle presencia y participación al espectador. Sin embargo, esta aparente inmediatez y apertura es irónicamente desmantelada por su incapacidad de sostener su acto "antiteatral” al tranformarse con demasiada frecuencia de performer a personaje, es decir, al revelar la vulnerabilidad de su identidad como performer. ${ }^{14}$

En última instancia lo significativo de esta fluctuante caracterización de Graciela es que nos acerca cada vez más a la metafórica sustitución que hace la obra de la figura del marido por la del autor, cuya relación con la performer, como veremos, también es una de gran tensión. Al meditar en torno a esta relación entre autor y performer tenemos que subrayar que uno de los factores que con más frecuencia destacan los estudiosos del arte performativo es el concepto de que el performer no es un mero intérprete de un texto literario ya existente, sino que es el creador de un acto o una acción (Carlson 92): "Unlike traditional actors, [performers] created their own projects-serving as writer, producer, director, designer, cast, and often carpenter and costumer as well” (Carlson 148). Sin embargo, Vanden Heuvel nos recuerda que aún cuando se reconoce que uno de los importantes mecanismos del arte performativo es el desplazamiento que el performer hace del autor como figura paternalista, también señala que la única forma de evitar la clausura y el control de este desplazamiento es cuando el performer, a su vez, permite ser desplazado, quizás por un espectador (12). En el caso de Graciela la ironía surge cuando su deseo de desmantelar las tradicionales estructuras de poder que controlan el espacio teatral y que nos permiten concebirla más bien como perfomer y no como personaje, se entremezcla con su deseo vehemente de desmantelar el poder que su marido tiene sobre ella, poder que ella no parece dispuesta a ceder o compartir con otros: "Mil gracias, pero al fin y al cabo es mi marido, y este pleito es sólo de él y mío, y nadie tiene que meterse” (29).

Este contrapunteo entre el triunfo y el fracaso de Graciela como performer nos obliga a cuestionar la propia presencia de la protagonista en contraste con la ausencia de su marido. Como hemos sugerido, el triunfo de Graciela como performer debía otorgarle la credibilidad

\footnotetext{
${ }^{14}$ Señalamos al comienzo de este ensayo cómo la construcción dramática de Graciela pretende subvertir su realidad como personaje para destacar más bien su perfil de performer. Aquí, sin embargo, reconocemos que Graciela no logra sostener esta transformación, revirtiendo con excesiva frecuencia a su "papel” de personaje.
} 
necesaria y el evidente distanciamiento de todo lo que represente una fuerza de autoridadlo teatral, lo social, lo institucional—como medio de afirmar su presencia. Es justamente el énfasis en el carácter performativo de Diatriba lo que debía prepararnos en cierto sentido para "dejar de oír" la voz de la propia Graciela, es decir, para que la propia actividad performativa problematice la presencia del performer al final de la obra cuando su voz se va disipando hasta ser opacada por la música de mambo de la fiesta que su marido ha organizado para "celebrar" su aniversario de plata. Es decir, si concebimos la pieza como un intento de diluir toda autoridad para darle paso a unas estructuras más representativas que sean capaces de iluminar las virtudes y las fallas del propio performance, entonces el silencio final de Graciela debía ser emblemático de esta apertura espacial, lingüística y artística.

Sin embargo, las perspectivas del mencionado fracaso de Graciela como performer nos obligan a preguntarnos si la protagonista ha logrado, como consecuencia de esta desaparición final, disipar el poder que ejerce su marido sobre ella, o más bien ha sucumbido nuevamente a él al perder su propia voz. ¿Vemos Diatriba de amor como un grito feminista de una mujer que reclama su espacio y su voz, o resulta más bien en el silencio paralizante de Graciela? ¿Vinculamos el fracaso y las contradicciones de Graciela a su compleja personalidad, o más bien los vinculamos con la propia naturaleza del género performativo que parece caracterizarse por su capacidad de cambio y constante redefinición? ¿Cómo entendemos entonces el doble giro de tuerca en donde una obra dramática y su protagonista pretenden esconder su realidad teatral tras la máscara del performance, pero al fracasar en su intento quedan aun más en evidencia tanto su identidad textual como su carácter autoritario?

Es precisamente al pensar en Diatriba desde un ángulo tradicional del teatro, es decir, como espectáculo dramático cuyo origen y poder reside en un autor-García Márquezquien crea unos personajes, que tendríamos que interpretar su desaparición final y el silencio escénico de la performer como emblema de su fracaso. La propia Graciela no parece entender del todo las sutilezas y contradicciones del performance, siendo obvio que su desaparición y silencio final no son voluntarios: a punto de concluir la pieza, escuchamos con dificultad las palabras de Graciela quien le grita a los músicos, “¿Déjenme hablaaaaar!” (69). Vemos así a la protagonista aferrarse a su recién adquirida autoridad, sin reconocer que la noción que prevalece dentro del discurso performativo no es la de sustituir la autoridad sino de disiparla. ¿Pero quién, entonces, le impone este silencio y dispone su desaparición?

Justamente al tomar en cuenta el deseo de desmantelar la autoridad y de afimar lo ausente y carente de poder a través del discurso performativo, nos acercamos a la metafórica sustitución que hace la obra de la figura del marido por la del autor. Suponer que la protagonista se transforma de personaje de un drama tradicional a una performer, metaforiza el deseo de la figura autorial de desplazar su propia autoridad a otro, de desaparecer para colocar la atención y responsabilidad, los posibles triunfos o fracasos, en manos de otroes decir, de la protagonista única, Graciela — quien a su vez ha estado intentando presentarse a sí misma como ser autónomo e independiente a través de la retórica del performance. Pero, ¿por qué este deseo de transferir la autoridad creativa a otro? ¿Se trata de un acto de 
conciencia artística por parte del autor? ¿ ¿ se trata más bien de subrayar que cualquier intento de desplazar el poder autorial no es sino una mera ilusión? ${ }^{15}$

Como hemos sugerido antes, en un primer nivel podríamos reconocer en Diatriba ciertas estrategias performativas que han sido asociadas con la rebeldía femenina y con el discurso feminista (ver Forte). Sin embargo, resulta irónico reconocer que este deseo de otorgarle poder al otro- en este caso a Graciela_-no es sino un intento por crear la falsa ilusión de una mujer y de una obra que procuran ser abiertas, independientes y rebeldes. Por ejemplo, vemos cómo la caracterización de Graciela, cuyo estatus social privilegiado debía proporcionarle libertad y seguridad, se contrapone en la obra con una problemática realidad en donde vivir dentro de este mundo privilegiado es precisamente lo que establece sus límites vitales, psicológicos e incluso artísticos. Es pues evidente que la opulencia económica y el prestigio social dentro de los cuales vive Graciela sólo le brindan una libertad condicionada, y por lo tanto, contradictoria. En última intancia ni Graciela ni la pieza logran emblematizar la deseada independencia y apertura que asociamos con el acto performativo, revelándose así el carácter ambivalente del performance femenino: "By claming the right to perform, women claim public space, space reserved for men. This is a liberating act in that it allows women to escape the confines of their private spaces, act on a public stage, and communicate in ways formerly unavailable. However, it is also a dangerous practice. As she shucks off her private identity, a woman becomes public, open to ridicule and worse" (Gladhart 139).

Insistimos entonces que la ironía de la obra radica en reconocer que el sentido de independencia vital y artística de Graciela desaparecen ante lo que consideramos su fracaso como performer, es decir, como creadora y como mujer que pretende liberarse de unas ataduras sociales y escénicas. Si asumimos que uno de los aspectos esenciales de la pieza de García Márquez es problematizar el concepto de identidad y libertad artística a través del arte performativo_el cual tiende a desplazar las funciones tradicionales del autor-, entonces tendríamos que asumir que el rotundo fracaso de Graciela está vinculado con el (¿premeditado y conveniente?) fracaso del propio autor de teatralizar su desaparición autorial, es decir, de desaparecer como centro y razón de ser del texto, como figura masculina con poder, autoridad y fama. Este consciente fracaso expresa su carácter perverso al darnos cuenta de que en el momento en que reconocemos que un autor plantea metafóricamente su desaparición como figura de autoridad está inevitablemente llamando nuestra atención hacia sí mismo y hacia su propia presencia en el texto dramático.

Es justamente como parte de una dinámica de poder entre autor y performer que también se manifiesta el conflicto entre hombre y mujer-conflicto que a su vez nos permite ver la relación que se establece entre Diatriba de amor y el arte performativo como parte de una exploración del autor de su propia relación con el arte. La visión de Graciela como performer mujer, inevitablemente nos conduce a examinar ciertos rasgos particulares dentro de las teorías del acto performativo que han establecido un vínculo estrecho entre éste y la mujer: "In the early 1970s ... the rise of the women's movement provided a much more favorable climate for performance work created by women and concerned with their private

\footnotetext{
${ }^{15}$ Recordemos aquí las palabras del segundo epígrafe de este trabajo: “There is nothing more illusory in performance that the illusion of the unmediated" (Blau 164-65).
} 
and public experience as women” (Carlson 147-48). Pero sobre todo, Carlson nos recuerda que la mujer se siente atraída hacia el performance porque le permite control personal (148), el cual manifiesta con frecuencia a través de la presentación de material autobiográfico: "Concerns with self, self image, and the social self... were central concerns to the emerging women's movement of the same period [early 1970s] —and this movement found in performance an important field for its expression” (150). ${ }^{16}$

En un primer nivel, parecería obvio destacar el carácter feminista de Diatriba de amor, pues se trata de una mujer de clase alta que finalmente parece rebelarse contra la hipocresía de las estructuras sociales que la dominan y contra un marido débil, acomodaticio e infiel. ${ }^{17}$ Vemos así que la rebeldía de Graciela va más allá del mero acto de despedazar la vajilla y otros objetos de valor al iniciarse el drama, como símbolo de que ha llegado a sus límites de tolerancia: "Me voy por mí, y por nadie más, harta de una suerte mezquina que me lo ha dado todo menos el amor" (62). No obstante, es precisamente esta caracterización del acto performativo de una mujer-a través del cual se afirman sentimientos de autodefinición y control-lo que nos permite reconocer la tensión que propone la obra entre voz femenina (monólogo de Graciela) y el aparente silencio y ausencia de las voces masculinas representadas por el marido/maniquí, e implícitamente por el autor. No parece casual entonces que García Márquez haya puesto en escena a una mujer rebelde y que, desde nuestra perspectiva, haya creado la ilusión de que se trata de una performer quien crea su propio proyecto ejerciendo de escritora, productora, directora, diseñadora, elenco, carpintera e incluso de clienta (Carlson 148). No nos sorprende ver en Diatriba a una mujer vociferante que quiere que conozcamos sus orígenes, sus sacrificios, su ignorancia y sus frustraciones vitales y psicológicas al sentirse atada a una relación infructuosa. Es su aparente papel de performer lo que le permite a Graciela enfrentarse a un público en sus propios términos, con su propia versión de los hechos, con un lenguaje que parece propio.

No obstante, Diatriba nos obliga a indagar en la paradójica naturaleza feminista de la pieza en general y de la protagonista en particular. Como hemos señalado, por un lado, Diatriba construye sagazmente la ilusión y presencia de una performer quien es percibida como un ser autónomo que se construye a sí misma y que cree poder establecer su propio dominio temporal, físico y psicológico. Por otro lado, aún cuando reconocemos el carácter rebelde de Graciela, nos enfrentamos a la sumisión de ésta ante las fuerzas tradicionales de carácter textual y teatral que la dominan, e incluso ante las inconsistencias del propio género del performance. Es decir, vemos a un personaje femenino que en su papel de mujer revela

\footnotetext{
${ }^{16}$ Como parte de esta relación entre feminismo, performance y autobiografía resulta importante subrayar el vínculo que ha sido establecido entre los actos performativos de mujeres y la temática de la identidad tanto sexual, social, política como artística (ver Carlson 153). Por ejemplo, Carlson destaca que los "solo performance" y los monólogos se han asociado durante finales de la década de los ochenta y principios de los noventa particularmente con performers feministas y homosexuales (115). Como parte de esta amplia problematización de la identidad que abarca el discurso feminista, otro aspecto que nos ha llamado la atención ha sido precisamente el de la identidad artística, caracterizada principalmente por el juego entre presencia y ausencia autorial.

${ }^{17}$ Resulta de interés subrayar el comienzo de la reseña que hace Bárbara Mujica de la obra: "Gabriel García Márquez has sometimes been accused of misogyny, but in this mordant one-act play he takes the woman's side" (60).
} 
sus insatisfacciones psicológicas y físicas, pero que, aún dentro de su rebelión, la concebimos como marioneta de otras voces-que podríamos llamar marido, hijo, suegra, pero sobre todo, autor. Paradójicamente reiteramos entonces que es el fracasado papel de la performer lo que nos permite ver la insistente e irónica presencia de la figura autorial-García Márquez-quien juguetonamente crea la ilusión de que también es un mero maniquísilente e inmóvil—otorgándole una falsa independencia y autoridad a Graciela, pero a la vez insertándose como el ser que controla el texto y el escenario. ${ }^{18}$

Hemos visto hasta ahora el tira y afloja entre la presencia y el poder de dos “autores”García Márquez y Graciela_-, pero irónicamente esta problemática parece culminar al final de la pieza en la aparente ausencia de ambos: el primero al cederle el poder performativo y autorial a Graciela, y la segunda al quedar silenciada ante las fuerzas sociales y económicas que atentan contra su rebelión de origen antiteatral y anti-institucional. Sin embargo, a pesar del carácter ilusorio de esta doble desaparición, lo que parece más seductor es suponer que la diatriba contra un hombre (maniquí) sentado que lee el periódio y el acto de quemar tanto al marido-lector como al texto que éste lee, emblematiza la violenta destrucción de una figura que en el plano vital ha humillado a la esposa (el marido) y en el textual representa la autoridad masculina (el autor). La sagacidad de la pieza reside entonces en suponer que se trata de una serpiente que se muerde la cola: por un lado, habíamos sugerido que la figura autoritaria y creadora parece cederle el espacio vital y escénico a Graciela, y por otro vimos cómo Graciela logra simbólicamente asesinar tanto al marido- “autor” de su desgraciacomo al que la crea y le otorga una aparente autonomía escénica a través del acto performativo. Sin embargo, lo que resulta más obvio es que ni Graciela consolida el poder que en un principio cree tener, ni la figura del afamado autor logra desaparecer al fracasar conscientemente en su intento por crear una ilusión de performance y al cuestionar su propio intento de cederle verdaderamente la autoridad y el espacio escénico a otras voces y a otros discursos: “Absolute powerlessness”—señala Vanden Heuvel refiriéndose al tira y afloja de Samuel Beckett ante la subversión del poder autorial—_is as illusory as abolute power, and, it seems, equally corrupting” (91).

Ante este múltiple proyecto de teatralizar tanto la textualidad como el ángulo performativo de Diatriba a la vez que ambos son desmantelados, es pertinente mencionar el paralelismo entre la problemática de la autoridad que presenta García Márquez en Diatriba y el reconocimiento por parte de Beckett de que el intento de subvertir el poder autorial, en última instancia no da frutos (Vanden Heuvel 92):

The working out of this formation achieves, in Beckett's later work, a kind of ambivalent response to the conflict between authorial control and performative openness, power and powerlessness. Instead of trying to create a completely nonrelational, nontextual art, Beckett is satisfied to commingle elements of traditional textuality with more subversive performance strategies; and the result is an ironic and complementary, rather than dominant or hierarchical, relationship between the two. (Vanden Heuvel 193) ${ }^{19}$

\footnotetext{
${ }^{18}$ Reiteramos aquí las palabras de Gladhart sobre el problemático movimiento de la mujer del espacio privado al espacio público, pues, por un lado parece ser un acto liberador, pero por otro puede convertirse en una práctica peligrosa al exponerla al ridículo (139).

${ }^{19}$ Resulta de interés mencionar aquí el posible vínculo de Diatriba de amor con el monólogo Happy Days (1961) de Samuel Beckett. En esta pieza, Beckett establece una conflictiva relación entre Winnie,
} 
Es precisamente a raíz de las contradicciones genéricas y filosóficas de Diatriba de amor que reconocemos que no se trata de un performance, sino más bien de una pieza cuyo ángulo más complejo es que asume la identidad de un performance no siéndolo. Es decir, Diatriba de amor contra un hombre sentado sagazmente construye una retórica que sustenta la ilusión de un performance que es capaz de subvertir tanto el discurso tradicional, que conjuga texto y producto dramático, como el discurso performativo, que contrapone el producto dramático con la dimensión antiteatral y anti-institucional de éste.

Parecería entonces que tanto Graciela como el propio García Márquez desempeñan papeles a la vez complementarios y contradictorios, pues cada uno de ellos-en espacios y contextos diferentes - teatralizan una lucha entre la afirmación y el desmantelamiento de la autoridad. Por un lado, el autor de Diatriba parecería querer enmascarar su autoridad al recurrir a los códigos del performance, los cuales han sido caracterizados por su deseo de desmantelar la imagen de un autor que crea a un personaje el cual es representado por una actriz. Graciela, por su parte, se mueve dentro de una realidad y un espacio ambiguo al ser un personaje construido siguiendo los parámetros generales del performer como ser independiente y autónomo - encargada de la vestimenta, las luces y el sonido y quien bien podía haber colocado en escena el maniquí de su marido-pero quien fracasa en su intento por romper con el carácter textual y representacional del teatro y de su vida. La consecuencia inmediata e irónica de esta serpiente que se muerde la cola, es que el cuestionamiento del poder autorial a su vez termina siendo cuestionado y la obra parece convertirse, en ciertos niveles, en la tematización y teatralización del poder y la autoridad creativa.

Es por ello que al examinar esta pieza de García Márquez a la luz de ciertas teorías del performance que plantean la dicotomía entre su dimensión antiteatral (Taylor 49-50) y su carácter de espectáculo dramático, se destaca el choque entre dos fuerzas autoriales que pretenden enmascarar su poder intentando crear la ilusión de un juego entre presencia y ausencia, entre el autor y la performer, entre el control del texto, el control del escenario, y el control del acto creativo. Como hemos visto, sin embargo, el juego no parece ser parejo, y la texualidad y la presencia autorial no desaparecen en ningún momento. En última instancia, el supuesto desplazamiento de la autoridad hacia la figura de la performer o la supuesta desaparición de ambos autores termina siendo un gesto seductor pero ilusiorio, pues al traer a la superficie su problemática realidad tanto textual como performativa y al tematizar este doble discurso, Diatriba de amor parece más bien estar creando un espacio interactivo entre texto y performance en donde se reflexiona desconstructivamente tanto en torno a los parámetros del arte tradicional como del arte performativo, y en última instancia en torno a la presencia/ausencia de la figura de autoridad. ${ }^{20}$

mujer de unos 50 años enterrada inicialmente hasta la cintura y luego hasta el cuello, y Willie, hombre de unos 60 años quien vive detrás del montículo de tierra y quien se caracteriza por su posición a gatas. El largo monólogo de Winnie es interrumpido en muy pocas ocasiones por Willie, y al igual que la diatriba de Graciela, se caracteriza por su tono de reproche y frustración. La vaciedad en las vidas de estas dos parejas y el control que establecen ambas figuras femeninas tanto en Happy Days como en Diatriba de amor revelan, entre otras cosas, conflictos de poder y autoridad tanto sociales como teatrales, mentales como físicos, personales como colectivos.

${ }^{20} \mathrm{Al}$ examinar la actividad performativa de The Wooster Group, en particular la pieza Sakonnet Point descrita como "a self-referenctial metacommentary on the individual 'performative' psyche of 
Resulta entonces de particular interés subrayar que el escritor más ponderado del siglo XX no pierde la oportunidad de proyectarse—a través de la problemática voz de Graciela— hacia un nuevo género, hacia un nuevo espacio y hacia unos nuevos planteamientos que exigen otro léxico y que conllevan otras expectativas a las acostumbradas por el autor y por su público lector. Es por ello que reconocemos en Diatriba de amor contra un hombre sentado la parodización de la figura del autor (por el propio autor) y la implícita reflexión que hace el artista en torno a su propio arte. Podríamos incluso argüir que la construcción temporal de la pieza — la interacción de pasado, presente e incierto futuro de la protagonistaforma parte de un juego consciente en donde la supervivencia del autor está precisamente en juego. ¿ ¿Trascenderá la obra del Nobel colombiano la apoteosis que alcanzó durante el siglo XX? ¿ ¿O tendrá que ceder éste a las fuerzas transformativas de nuevas y seductoras formas artísticas? ¿ ¿Tendrá que asumir otras voces y otras máscaras y luchar mano a mano para preservar su autoridad y poder autorial-fuerzas que aparecen problematizadas (tanto multiplicadas como silenciadas) en Diatriba de amor? ¿O aceptará en buena lid que es necesario cederle el espacio a otras figuras menos asociadas con el poder tradicional, como lo es, por ejemplo, una mujer performer?

A pesar del carácter aparentemente perogrullesco de estas interrogantes, no es posible negar que a lo largo de su producción narrativa, pero sobre todo en sus novelas y cuentos más recientes, García Márquez ha tematizado de forma explícita su propia presencia autorial y su supervivencia temporal. Su peregrinaje como autor, caracterizado tanto en el prólogo como en los relatos de Doce cuentos peregrinos (1992), en el prólogo a Del amor y otros demonios (1994) y en un texto tan fascinante y complejo desde una perspectiva autorial como lo es Noticia de un secuestro (1996), sugiere la presencia de una voz autorial que desea ser vista y reconocida como tal por el lector-voz que se rehúsa a desaparecer y que parecería dispuesta incluso a cambiar de género literario (de la narrativa al teatro y al arte performativo) e incluso de género sexual (Graciela o Gabriela) asegurándose así una característica entrada al nuevo milenio y un juguetón peregrinaje post mortem.

\section{Biblografía}

Barthes, Roland. "The Death of the Author”. Image, Music, Text. Stephen Heath, trad. Nueva York: Hill and Wang, 1977. 142-48.

Blau, Herbert. "Universals of Performance; or, Amortizing Play”. The Eye of Prey: Subversions of the Postmodern. Bloomington y Indianapolis: Indiana University Press, 1987. 161-88.

Cano, Luis. "Asedio a la palabra: Oralidad y escritura en Diatriba de amor contra un hombre sentado". Trabajo final para el seminario graduado "Corrientes postmodernas de teatro hispanoamericano contemporáneo”.

Spalding Gray and on the abstract theme of loss" (107)—Vanden Heuvel señala: "Again, as we have already seen in Beckett and as will later appear in the work of Wilson and Shepard, such ironic doublecoding of the functions between performance and textuality is an integral part of the theatrical experience. It is the mechanism by which a new mutualist space is carved out, a space that can bear meanings perhaps unbearable or unspeakable within a dominant hierarchy that privileges text or performance" (113). 
Carlson, Marvin. Performance: A Critical Introduction. Londres y Nueva York: Routledge, 1996.

Féral, Josette. "Performance and Theatricality: The Subject Demystified”. Terese Lyons, trad. Modern Drama 25/1 (1982): 170-81.

Forte, Jeanie. “Women's Performance Art: Feminism and Posmodernism”. Performing Feminisms: Feminist Critical Theory and Theatre. Sue-Ellen Case, ed. Baltimore y Londres: The Johns Hopkins University Press, 1990. 251-69.

García Márquez, Gabriel. Diatriba de amor contra un hombre sentado. Bogotá: Arango Editores, 1994.

Geis, Deborah R. Postmodern Theatric [k]s: Monologue in Contemporary American Drama. Ann Arbor: The University of Michigan Press, 1993.

Gladhart, Amalia. The Leper in Blue: Coercive Perfomance and the Contemporary Latin American Theatre. Chapel Hill: University of North Carolina Press, 2000.

Grau, María Mercedes. “Celebran el performance y la caribeñidad en congreso Caribe 2000”. Díalogo (Universidad de Puerto Rico-Abril 1999): 16.

Kronik, John W. "Invasions from Outer Spaces: Narration and the Dramatic Art in Spanish America”. Latin American Theatre Review 26/2 (1993): 25-47.

Moliner, María. Diccionario de uso del español. 2 tomos. Madrid: Editorial Gredos, 1982.

Mora, Rosa. "Una obra teatral de García Márquez abre una nueva colección de libros baratos”. El País (3 abril 1995): 32.

Morales, Ed. “Too much, too long: Diatriba de amor (Contra un hombre sentado)”. Village Voice (23 abril 1996): 87.

Mujica, Bárbara. “Intimate worlds, loveless bonds: Diatriba de amor contra un hombre sentado (Diatribe of Love against a Seated Man) by Gabriel García Márquez”. Americas (Edición en inglés) 47/3 (1995): 60.

Taylor, Diana. "Negotiating Performance”. Latin American Theatre Review 26/2 (1993): 49-57.

“Opening Remarks”. Negotiating Performance: Gender, Sexuality, and Theatricality in Latin/o America. Diana Taylor y Juan Villegas, eds. Durham y Londres: Duke University Press, 1994. 1-16.

Vanden Heuvel, Michael. Performing Drama/Dramatizing Performance: Alternative Theater and the Dramatic Text. Ann Arbor: The University of Michigan Press, 1991. 